University of Wollongong

Research Online

Faculty of Social Sciences - Papers (Archive) Faculty of Arts, Social Sciences \& Humanities

$1-1-2018$

Children's sports participation and self-regulation: Bi-directional longitudinal associations

Steven J. Howard

University of Wollongong, stevenh@uow.edu.au

Stewart A. Vella

University of Wollongong, stvella@uow.edu.au

Dylan P. Cliff

University of Wollongong, dylanc@uow.edu.au

Follow this and additional works at: https://ro.uow.edu.au/sspapers

Part of the Education Commons, and the Social and Behavioral Sciences Commons

Research Online is the open access institutional repository for the University of Wollongong. For further information contact the UOW Library: research-pubs@uow.edu.au 


\title{
Children's sports participation and self-regulation: Bi-directional longitudinal associations
}

\author{
Abstract \\ Early self-regulation is essential to positive life outcomes and sports are speculated to generate self- \\ regulatory improvements. Preliminary research supports this assertion, showing some sports might yield \\ short-term self-regulatory improvements and elite athletes tend to excel in cognitive functions underlying \\ self-regulation. What remains unclear is whether sports improve self-regulation or better self-regulators \\ engage in sport. We investigated whether sport participation in early childhood (4-5 years) predicted \\ change in children's self-regulation two years later; and early self-regulation (4-5 years) predicted change \\ in sports participation two years later. Data were drawn from the Longitudinal Study of Australian \\ Children, which consisted of 4385 children with valid sports participation data at age 4-5 years. Self- \\ regulation was indexed by parent-, teacher-, and observer-report data. Results indicated that young \\ children who participated in individual sports demonstrated marginally but significantly higher self- \\ regulation than those who did not participate. Participation in team sports did not predict change in self- \\ regulation. Moreover, children with poor self-regulation were less likely to participate in sports. The \\ findings provide partial support for hypotheses of bidirectional associations between sport participation \\ and self-regulation in young children.

\section{Disciplines} \\ Education | Social and Behavioral Sciences

\section{Publication Details} \\ Howard, S. J., Vella, S. A. \& Cliff, D. P. (2018). Children's sports participation and self-regulation: Bi- \\ directional longitudinal associations. Early Childhood Research Quarterly, 42 140-147.
}


Children's Sports Participation and Self-Regulation: Bi-Directional Longitudinal Associations

Steven J. Howard ${ }^{\mathrm{a}}$, PhD, Stewart A. Vella ${ }^{\mathrm{a}}, \mathrm{PhD}$, \& Dylan P. Cliff ${ }^{\mathrm{a}}, \mathrm{PhD}$

Affiliations: aEarly Start and School of Education, Faculty of Social Sciences, University of Wollongong, New South Wales, 2522, Australia

Address correspondence to: Steven Howard, School of Education, University of Wollongong, New South Wales, 2522, Australia; Email stevenh@uow.edu.au; Phone +61 242215165. 


\title{
Children's Sports Participation and Self-Regulation: Bi-Directional Longitudinal
}

\section{Associations}

\begin{abstract}
Early self-regulation is essential to positive life outcomes and sports are speculated to generate self-regulatory improvements. Preliminary research supports this assertion, showing some sports might yield short-term self-regulatory improvements and elite athletes tend to excel in cognitive functions underlying self-regulation. What remains unclear is whether sports improve self-regulation or better self-regulators engage in sport. We investigated whether sport participation in early childhood (4-5 years) predicted change in children's selfregulation two years later; and early self-regulation (4-5 years) predicted change in sports participation two years later. Data were drawn from the Longitudinal Study of Australian Children, which consisted of 4385 children with valid sports participation data at age 4-5 years. Self-regulation was indexed by parent-, teacher-, and observer-report data. Results indicated that young children who participated in individual sports demonstrated marginally but significantly higher self-regulation than those who did not participate. Participation in team sports did not predict change in self-regulation. Moreover, children with poor selfregulation were less likely to participate in sports. The findings provide partial support for hypotheses of bidirectional associations between sport participation and self-regulation in young children.
\end{abstract}

Keywords: self-regulation, sport, sports participation, physical activity, early childhood, preschool 
There has been recent speculation that, in addition to the established physical, health, social, emotional, and psychological benefits of sports participation (for reviews see Eime, Young, Harvey, Charity, \& Payne, 2013; Fraser-Thomas, Cote, \& Deakin, 2005), there might also be wide ranging cognitive benefits from participating in sports. Foreshadowing this possibility, evidence of a link between physical activity and academic results has been shown in cross-sectional, longitudinal, and experimental studies (e.g., Carson et al., 2015; Coe, Pivarnik, Womack, Reeves, \& Malina, 2006; Dwyer, Sallis, Blizzard, Lazarus, \& Dean, 2001; Shephard, 1997). Further, there is evidence that participation in sport in high school is associated with a broad range of academic benefits (e.g., grades, attendance, aspirations; Eccles \& Barber, 1999; Whitley, 1999). However, the cognitive mechanisms underlying these intellectual benefits of sports participation are less clear.

More recently, there has been suggestion that participation in sports may enhance core cognitive capacities underlying self-regulatory behaviours. These cognitive capacities, often bundled as 'executive functions' (EFs), involve the capacity and control of attention to: (i) activate and work with information in mind (working memory); (ii) resist urges, impulses, and distractions that are irrelevant to our goals or context (inhibition); and (iii) flexibly shift attention to new information and demands (cognitive flexibility) (Diamond, 2016). These cognitive control abilities combine, along with motivation, goal setting, and problem solving, to enable children's self-regulatory ability to control their thinking, behaviours, emotional reactions, and social interactions despite contrary urges, impulses, and distraction (Hofmann, Schmeichel, \& Baddeley, 2014). Given the foundational importance of self-regulation, status and change of which robustly predicts children's academic success and health, wealth, and criminality in adulthood (Moffitt et al., 2011), it is thus unsurprising that success of any EF intervention is typically gauged by the extent to which its benefits transfer to self-regulatory improvement. Research on the intellectual benefits of physical activity is no exception, which 
has similarly sought to identify potential EF and self-regulatory benefits (e.g., academic achievement, prosocial and anti-social behaviour, persistence or frustration in response to challenge; Davis et al., 2007; Lakes \& Hoyt, 2004). While self-regulation already develops rapidly in early childhood (Montroy, Bowles, Skibbe, McClelland, \& Morrison, 2016), this research has increasingly focused on younger years given suggestion that early intervention may produce more pronounced, stable, and lasting change (Wass, Scerif, \& Johnson, 2012), and greater return on investment (Heckman, 2006).

Sports participation appears to be well suited to provide the qualities speculated to be essential for EF and self-regulatory improvements. Specifically, Diamond and Ling (2016) speculate that successful intervention requires activities that: tax and continually challenge EFs, preferably in more ecologically valid contexts to promote transfer of benefits to nontrained situations; can sustain a continually increasing EF challenge over a prolonged period, maximizing dose and duration; can minimize factors that undermine executive functioning (e.g., stress, lack of sleep, loneliness, poor health); and are genuinely enjoyable and socially connected. It is well established that participating in physical activity, including sports, can improve the psychological (e.g., stress; Long, 1985; Schnohr, Kristensen, Prescott, \& Scharling, 2005), physiological (e.g., lack of sleep; Youngstedt, 2005), health (e.g., poor fitness, unhealthy weight; Cote \& Hay, 2002; Wankel \& Berger, 1990) and social factors that can undermine EFs (e.g., lack of social connectedness; Hansen et al., 2003; Holt et al., 2011; Wiersma et al., 2008). It remains to be established, however, whether sports also engage, challenge, and improve EFs and, by extension, lead to self-regulatory change.

Conceptually, it is easy to see how participation in sports might engage and continue to challenge participants' EFs. In the case of team sports, players must use working memory to maintain rules and strategies in mind, recall where teammates and opposing players are in space and anticipate their actions, all of which are conditioned by whether you are on offence 
or defence. A player must also inhibit the egocentric impulse (in a Piagetian sense) to retain the ball without passing or, conversely, immediately and unconditionally offload the ball if imposing defenders approach. Inhibition would also be involved in resisting distraction from players outside the play and spectators on the sidelines. Further, players need to have the cognitive flexibility to adapt to ever-changing game demands and situations, shift attention between players and strategies, and when plans fail think creatively to find an appropriate solution. Even amongst young children who often participate in modified forms of sport, the need to remember the sport's aims and rules, inhibit impulses to simply chase the ball, and flexibly switch from offence to defence could continually challenge young children's morelimited EFs. Similarly, within individual sports, even young participants may require more intra-personal focus to control their actions (e.g., form, posture, sequence), with greater levels of support from adults (i.e., parent, coach) to help direct and control their limited attentional resources.

While there is comparatively more research establishing an effect of individual sports on EFs (e.g., Tae-Kwon Do; Lakes \& Hoyt, 2004), there is currently limited empirical evidence that participation in team sports does improve EF, and none that evaluates this experimentally (Diamond, 2016). Research on the effects of team sports has largely examined the association between EFs and 'elite-ness' in sport. For instance, Vestberg, Gustafson, Maurex, Ingvar, and Petrovic (2012) found positive associations between EFs and objective sports performance (e.g., goals and assists in soccer). They also found that those participating in division soccer (i.e., high-performing) displayed better EFs than a standardized norm group. Similarly, Voss, Kramer, Basak, Prakash, and Roberts (2009) found athletic expertise was positively related to performance on a range of higher-order cognitive tasks, most notably amongst those playing interceptive sports. There is also evidence that athletes-even those who are not performing at elite levels-show higher EFs than non-athletes (Jacobsen \& Matthaeus, 2014). In reporting 
these results, however, the researchers noted their inability to determine whether higher-EF individuals are more likely to become athletes or EFs improve as a result of participation in sports.

There is little experimental evidence investigating the directionality or reciprocal nature of the association between sports participation and self-regulation. Further, the research that does exist has looked almost exclusively at the effect of sports participation on EFs. Chang, Tsai, and Chen (2013), for example, found inhibition gains after an 8-week soccer program, although the strength of these findings was mitigated by the lack of a control group. There is also some evidence that open-skill sports participation may be an EF-protective factor among athletes with disabilities commonly characterized by EF impairment (Russo et al., 2010). While this research is far from conclusive, and examines only one possible direction of this association, these results are nevertheless suggestive. That is, if individual and team sports improve self-regulation via improvement in EFs, this would suggest a cognitive mechanism for many of the intellectual benefits of sport. Similarly, if better EFs are associated with uptake and maintenance of sports participation, this suggests a facilitator (and barrier) to participation in sport that may be a viable target for intervention.

Despite this apparent link between participation in sports and EFs, directionality of the association remains unclear. One possibility is that participation in sports promotes EF and self-regulatory development. This possibility has been widely hypothesized (e.g., Best, 2012; Diamond \& Lee, 2011; Diamond \& Ling, 2016), but has not been clearly established through longitudinal or experimental research. Conversely, those with better EFs may be more likely to enrol and remain in sports (Piché, Fitzpatrick, \& Pagani, 2012), since EFs are essential for success in the intellectual aspects of sport (Vestberg et al., 2012; Voss et al., 2009) and we tend to better enjoy and persist in activities that we are good at (Holbrook, Chestnut, Oliva, \& Greenleaf, 1984). This possibility has been speculated, yet has only preliminary support from 
studies with limited sample size, and demographic and socio-economic diversity (Jacobsen \& Matthaeus, 2014) or studies that did not investigate bi-directionality of associations (Piché et al., 2012).

The current study thus sought to evaluate, using a large-scale, nationally representative, and longitudinal dataset, the extent to which: sport participation (any, team, or individual) in early childhood (4-5 years) predicted self-regulation change two years later (6-7 years); and children's early self-regulation (4-5 years) predicted change in sports participation two years later (6-7 years). This focus on these early years was important given early interventions, in particular, are suggested to produce more pronounced, stable, and lasting change (Wass et al., 2012), and are more likely to produce greater return on investment (Heckman, 2006). While preliminary analyses considered participation in any form of sports, given disparities in the available evidence for team and individual sports, subsequent analyses looked at these forms of sport separately. In line with prior speculation and research (Best, 2012; Diamond \& Lee, 2011; Diamond \& Ling, 2016; Jacobsen \& Matthaeus, 2014) it was hypothesized that both individual and team sports participation would be associated with self-regulatory increases, even after controlling for baseline levels of self-regulation and known covariates. We also expected that better self-regulators would be more likely to take up and maintain participation in sports.

\section{Material and Methods}

\section{Participants}

Data were drawn from the Longitudinal Study of Australian Children (LSAC) (Sanson, Nicholson, Ungerer, Zubrick, \& Wilson, 2002). LSAC is a nationally representative and longitudinal study of Australian children that aims to examine the social, environmental, and economic impacts on children's development and well-being. Data used in the current study were largely collected from the child's primary parent (the person most responsible for care 
of the child, which was the child's mother in over $96 \%$ of cases), and was supplemented by observer- (trained interviewer and observer) and teacher-reported data. The majority of the study sample was attending some form of pre-school provision at 4-5 years of age $(96.3 \%$; Harrison, Ungerer, Smith, Zubrick, \& Wise, 2009), which roughly approximates that within the broader population (Baxter \& Hand, 2013). All data were drawn from LSAC's Birth (B) Cohort, which recruited 5107 children born in the baseline year (2004, Wave 1). This study used data from Waves $3(2008)$ and $4(2010)$, which had an $89.0 \%(N=4386)$ and $83.1 \%(N$ =4242) retention rate from baseline, respectively.

At baseline (Wave 3), when the children were age 4-5 years, 4385 children had valid sports participation data (99.9\% of available sample) and 2873 had complete self-regulation data (65.5\% of the available sample). Incomplete self-regulation data was typically due to missing teacher-report data, some items from which were included in the self-regulation composite index. After imputation, which occurred in cases for which at least $50 \%$ of the 20 constituent self-regulation items were available, 3951 children had valid self-regulation data (90.1\% of available sample). Two years later (Wave 4), when children were 6-7 years old, all children had valid sports participation data and 3352 children had complete self-regulation data (79.0\% of the available sample). After imputation, 4234 children had complete selfregulation data (99.8\% of the available sample). This corresponds to imputation of missing parent or educator (but not both) self-regulation items for $\sim 27 \%$ of cases at age 4 and $\sim 21 \%$ of cases at age 6. That full information was available for at least one of parent- or educatorreported self-regulation items provided a strong basis from which to impute missing selfregulation items. The Australian Institute of Family Studies Ethics Committee provided ethics approval for the LSAC study. Parents and teachers provided written informed consent for participation.

\section{Variables}


Self-Regulation. Children's self-regulation at 4- and 6-years of age was assessed using survey items, which closely paralleled those used by Moffitt et al. (2011) to create a robust, reliable, and strongly predictive self-regulation factor. Constituent items of this factor index the extent to which children can control their thinking and attention (e.g., sees tasks through to the end), behaviour (e.g., restless, overactive, cannot stay still for long), and emotions (e.g., often has temper tantrums). Following the protocols of Moffitt et al. (2011), parent- (11 items), teacher- (8 items), and observer-report ( 1 item) ratings of children's self-regulation were standardized and then averaged to create a single composite score. Standardization was necessary because items were rated on a scale from 1-3, 1-5, or 1-6, to indicate frequency or degree of the identified behaviour. The resulting factor maintained comparable significant inter-item correlations and strong internal consistency $(\alpha=0.82$ in the current study) as that reported in Moffitt et al.'s (2011) study $(\alpha=0.86)$. While the current factor was created in a constrained age range, compared to Moffitt et al.'s factor that combined data taken between ages 3 and 11 years, further analysis of this factor indicates that it strongly predicts academic outcomes into primary and secondary school and unhealthy lifestyle factors into adolescence (e.g., drug use, smoking, unhealthy weight; Authors, 2017). As such, psychometric reliability and longitudinal predictive validity both support the appropriateness of this factor. Further, correlation between age 4 and age 6 self-regulation was high $(r=.63)$. For correspondences between Moffitt et al.'s items and our matched items, see Table 1.

Sports Participation. Participation in team sports was measured using a parent-reported item at each of baseline and 2-year follow-up. At both time points, parents were asked if their child was currently participating in extracurricular team sports ('yes' or 'no'). Where parents answered 'yes', the child was categorized as a team sports participant at baseline or followup. Individual sports participation was captured by another parent-report item, the phrasing of which differed slightly at age 4 and 6. To assess children's participation in individual sports 
at age 4, parents were asked to indicate if their child was currently participating in swimming, dance, or gymnastics. Where parents answered yes to their child participating in one or more of these sports, the child was categorised as an individual sport participant. At age 6, parents were asked to indicate if their child was participating in individual sports ('yes' or 'no'), and were provided with exemplars (i.e., swimming, tennis, karate, gymnastics). While these changes in item phrasing potentially capture a greater range of sports than at age 4 , rates of individual sports participation remained relatively stable between age $4(N=2548 ; 56.4$ and to age $6(N=2355 ; 55.5 \%)$. It thus appears unlikely that the age 6 item was, in terms of participation, capturing dramatically different forms of sports participation than the age 4 $\operatorname{item}(\mathrm{s})$.

To assess change in sports participation from age 4 to 6 , we used these data to categorize children into one of four groups: (1) participating in sports at age 4 and 6 ("maintainers"); not participating in any sport at age 4 or 6 (“nonparticipants"); (3) participating in sports at age 4, but not at 6 (“dropouts"); and (4) not participating in sports at age 4, but participating at age 6 ("commencers"). These categories were created for 'any sport', 'team sport', and 'individual sport' participation.

Background and Demographic Factors. Six variables were also included as potential demographic predictors: child sex; indigenous status; family income; neighbourhood level socio-economic position; primary parent's education; and, the language spoken at home. The child's primary parent reported for all variables. Language spoken at home was coded as "English" or "Other". Indigenous status was coded as "Indigenous" or "Non-indigenous". Consistent with previous work (Magee, Caputi, \& Iverson, 2012; Vella \& Magee, 2015) family income was coded using interpretable cut-off criteria: <AUD\$1000/week (low); AUD\$1000-\$1999/week (medium); >AUD\$2000/week (high). From participants' home postal code, a measure of neighbourhood socioeconomic position was determined using the 
Socio-Economic Indexes for Areas (SEIFA) Index of Relative Socio-Economic Disadvantage (ABS, 2008). The primary parent's self-reported highest level of education was categorised as "less than high school", "high school", or "tertiary" education. Inclusion of demographic covariates was additionally important because, although the LSAC sample was nationally representative initially, factors that predicted missing data in Wave 3 included parents: born in Australia, not Indigenous, having completed high school, and higher SES.

\section{Analytic Strategy}

Missing self-regulation data were imputed, within each Wave, for participants with at least $50 \%$ of the items that comprised the self-regulation variable completed (i.e., at least 10 of the 20 items completed). Thus no imputed cases were missing both parent- and educatorreported self-regulation items. As such, missing data (typically teacher-rated data due to nonresponse) were well accounted for by the remaining self-regulation items on which there was full information. Missing data were imputed using the Expectation-Maximization algorithm in IBM SPSS statistical software's (version 19; IBM, Armonk, New York) missing value analysis. To evaluate whether early sport participation (4-5 years) predicted self-regulation change two years later, univariate general linear models were conducted with self-regulation scores at age 6 as the dependent variable, adjusted for self-regulation scores and demographic variables at age 4 . The final sample subjected to these analyses consisted of 3461 participants with sport participation data and demographics at age 4 and self-regulation data at age 6 . To also evaluate if children's early self-regulation (4-5 years) predicted change in sports participation two years later, multinomial logistic regression was conducted with the child's sports participation category as the dependent variable. The final sample subjected to these analyses consisted of 3465 participants with self-regulation and demographics at age 4 and sport participation at age 6 . Initially, analyses were run using the 'any sport participation' variable. However, to assess potential differences by type of sport participation, the analyses 
were repeated for both team and individual sports separately. Given large differences in sport participation by sex, we also investigated potential moderating effects for sex, or conducted additional stratified analyses by sex, where appropriate.

\section{Results}

The final sample consisted of a total 4385 participants (51.6\% male) aged $4-5$ years at baseline. Of this sample, $2750(62.7 \%)$ were sports participants at baseline. While estimates of sports participation at this age are not readily available, and estimates necessarily vary by how questions are posed, this falls within recent estimate ranges of 56\% (for 5- to 8-year old children; ABS, 2012) and 66\% (for 5- to 14-year old children; AHKA, 2016). More children participated in individual sports $(n=2548)$ than team sports $(n=587)$. A majority of children maintained sport participation $(n=2194 ; 48.5 \%)$ relative to those who dropped out $(n=426$; 9.4\%). A large number of children commenced participation in sports between baseline and 2-year follow up ( $n=854 ; 18.9 \%)$, while few children did not participate in sports at either time point $(n=629 ; 13.9 \%)$. At baseline, self-regulation scores were greater for females than males $(p<.001)$ and were greater as parental education increased $(p<.001)$. Table 1 gives estimated marginal means for self-regulation scores by selected demographic variables, as well as by sport participation status. Sensitivity analyses using non-imputed data confirmed all patterns of significance found with imputed data. Statistics are thus reported for the full, imputed dataset.

\section{Sport Participation Predicting Change in Self-Regulation}

Any sport participation. After adjusting for covariates, including baseline self-regulation scores, there was no difference in self-regulation at age 6 between those who participated in any form of organised sport at age 4 and those who did not $\left(F=1.58, p=.209, \eta^{2}<.01\right)$. Accordingly, there was no interaction between sex and sport on change in self-regulation $(F$ $\left.<0.01, p=.953, \eta^{2}<.01\right)$. 
Team sport participation. Similarly, after adjusting for demographics and baseline selfregulation scores, there was no difference in self-regulation at age 6 between those who participated in team sports at age 4 and those who did not $\left(F=1.08, p=.300, \eta^{2}<.01\right)$. There was no interaction between team sport participation and $\operatorname{sex}\left(F=1.80, p=.180, \eta^{2}<\right.$ $.01)$.

Individual sport participation. After adjusting for covariates and baseline self-regulation scores, those who participated in individual sports at age 4 had higher self-regulation scores at age 6 than those who $\operatorname{did} \operatorname{not}\left(F=7.44, p=.006, M_{\text {difference }}=0.04,95 \%\right.$ CI $\left.[0.01,0.07]\right)$, although the size of the effect was small $\left(\eta^{2}<.01\right)$. Again, there was no interaction between individual sport participation and sex on change in self-regulation $\left(F=0.56, p=.456, \eta^{2}<\right.$ $.01)$.

\section{Self-Regulation Predicting Change in Sport Participation}

Any sport participation. A multinomial logistic regression showed that, after adjusting for all covariates, self-regulation scores at age 4 years predicted change in sport participation between ages 4 and 6 years $\left(\chi^{2}=465.72, p<.001\right)$. Lower levels of self-regulation at age 4 predicted nonparticipation in any sport between the ages of 4 and 6 when compared to those who dropped out $(\beta=0.59$, Wald $=16.46, p<.001, \mathrm{OR}=1.80,95 \mathrm{CI}[1.36,2.40])$, those who commenced sport $(\beta=0.49$, Wald $=17.42, p<.001, \mathrm{OR}=1.63,95 \%$ CI $[1.30,2.05])$, and those who maintained their participation $(\beta=0.85$, Wald $=64.93, p<.001$, OR $=2.35$, 95\% CI [1.91, 2.89]). When the sample was stratified by sex, there were no differences in the pattern of results between boys and girls. Results indicated that with a relative difference of 1 SD less in self-regulation, these children were between 1.6 and 2.3 times more likely to have never participated in sport.

Team sport participation. After adjusting for all covariates, self-regulation scores at age 4 predicted change in team sport participation between ages 4 and 6 years $\left(\chi^{2}=575.31, p<\right.$ 
.001). Specifically, those with higher self-regulation scores at age 4 were more likely to have maintained participation $(\beta=0.44$, Wald $=12.26, p<.001, \mathrm{OR}=1.55,95 \% \mathrm{CI}[1.21,1.99])$ and commenced participation $(\beta=0.40$, Wald $=23.69, p<.001, \mathrm{OR}=1.49,95 \% \mathrm{CI}[1.27$, 1.76]) when compared to those who did not participate in sports. There were no differences in self-regulation between nonparticipants and those who dropped out of sport $(\beta=0.25$, Wald $=1.69, p=.194, \mathrm{OR}=1.29,95 \% \mathrm{CI}[0.88,1.88])$. Results indicated that with a relative difference of $1 \mathrm{SD}$ higher in self-regulation, these children were around 1.5 times more likely to have maintained or commenced participation in team sports at age 6 .

When the sample was stratified by sex, boys with higher self-regulation scores at age 4 were more likely to commence $(\beta=0.50, \mathrm{Wald}=23.91, p<.001, \mathrm{OR}=1.66,95 \% \mathrm{CI}[1.35$, 2.03]) or maintain participation $(\beta=0.64$, Wald $=20.10, p<.001, \mathrm{OR}=1.91,95 \% \mathrm{CI}[1.44$, 2.53]) in team sport than they were to be nonparticipants. Girls with higher self-regulation scores at age 4 were more likely to commence team sports participation when compared with nonparticipants $(\beta=0.28$, Wald $=4.14, p=.042, \mathrm{OR}=1.32,95 \% \mathrm{CI}[1.01,1.73])$; however, girls with higher self-regulation scores were no more likely to be maintainers than they were to be nonparticipants $(p=.257)$.

Individual sport participation. After adjusting for all covariates, self-regulation scores at age 4 predicted change in individual sport participation between ages 4 and 6 years $\left(\chi^{2}=\right.$ $451.53, p<.001)$. Lower levels of self-regulation at age 4 predicted nonparticipation in individual sports between the ages of 4 and 6 when compared to those who dropped out $(\beta=$ 0.50$, Wald $=20.64, p<.001, \mathrm{OR}=1.65,95 \% \mathrm{CI}[1.33,2.05])$, those who commenced sport $(\beta=0.23, \mathrm{Wald}=4.11, p=.043, \mathrm{OR}=1.25,95 \% \mathrm{CI}[1.01,1.56])$, and those who were consistent participants $(\beta=0.59$, Wald $=39.84, p<.001, \mathrm{OR}=1.80,95 \%$ CI $[1.50,2.17])$. Results indicated that with a relative difference of 1 SD less in self-regulation, these children were between 1.2 and 1.8 times more likely to have never participated in individual sports. 
When the sample was stratified by sex, boys with higher self-regulation scores at age 4 were more likely to maintain participation $(\beta=0.61$, Wald $=25.39, p<.001$, OR $=1.83,95 \%$ CI $[1.45,2.32])$ or drop out from individual sports $(\beta=0.65$, Wald $=19.50, p<.001$, OR $=$ $1.91,95 \%$ CI $[1.43,2.54])$ than they were to be nonparticipants. Girls with higher selfregulation at age four were more likely to be participants than nonparticipants in individual sports $(\beta=0.55$, Wald $=13.56, p<.001, \mathrm{OR}=1.74,95 \%$ CI $[1.30,2.34])$; however, girls with higher self-regulation were no more likely to drop out of individual sports than to be nonparticipants $(p=.065)$.

\section{Discussion}

Given the potential for sports participation to enhance self-regulation in young children, the current study sought to examine the bi-directional associations between these variables. Results of this study partially supported previous speculations, as participation in individual sports - but not team sports - weakly but significantly predicted positive change in children's self-regulation. Further clarifying this association, the current study showed that better selfregulators were more likely to be enrolled in sports at some stage in the pre-school and early elementary school period. This tended to be the case whether children maintained their sports participation or commenced later, and even if they dropped out of initial sports participation (except for team sports, where dropouts had similarly low self-regulation as nonparticipants). It was also notable that, despite clear differences between boys and girls in self-regulation and sports participation, there were few differences in longitudinal associations of sports on self-regulation, or self-regulation on sports participation. Our results suggest that particular types of sport may provide some limited self-regulatory benefits for young children, while it is more commonly those children who are higher in self-regulation that are engaging in these sports. 
The finding that certain types of sports might have self-regulatory benefits is consistent with theoretical and preliminary empirical accounts of the relationship between sports and self-regulation. That is, it has been speculated that sports may be particularly well suited to provide qualities essential for $\mathrm{EF}$, and thereby self-regulatory improvement. This includes an appropriate but increasing and sustained $\mathrm{EF}$ challenge, and minimizing those factors that can undermine successful self-regulation (Diamond \& Ling, 2016). In the current study there was no support for an overall association between team sports and subsequent self-regulation, and only limited evidence for individual sports overall being associated with improvement in selfregulation. Despite the individual sports association being weak, it is directionally consistent with preliminary evidence suggesting an effect of at least some forms of individual sports on development of cognitive control. Specifically, previous research has shown a positive effect of individual sports, such as Tae-Kwon Do, on early EFs and self-regulated behaviour (Lakes $\&$ Hoyt, 2004). These studies have tended to evaluate brief interventions, however, and acute and short-term outcomes of individual sports. At the same time, they have isolated particular forms of individual sport that may have more pronounced self-regulatory effects. Collapsing potentially more- and less-EF-promoting individual sports in the current study thus may have mitigated this association. Nevertheless, that an association was present is at least suggestive that previously suggested self-regulatory effects of some individual sports may persist over a more prolonged period of time.

In contrast, the current results contradict prominent hypotheses and preliminary evidence suggesting that team sports might also enhance self-regulatory abilities. For instance, Chang, Tsai, and Chen (2013) found inhibition gains in kindergarten-aged children after an 8-week soccer intervention (however, the strength of these findings is mitigated by lack of a control group). There is also evidence that participation in open-skill sports may be EF-protective for athletes with disabilities characterized by EF impairment (Di Russo et al., 2010). Our results 
indicate that, at least in this pre-school to early-elementary period, participation in any form of team sport was not associated with self-regulatory improvements. While contrary to our hypotheses, this is compatible with suggestions that EF and self-regulatory improvements require a maintained focus and control of attention (Diamond \& Ling, 2016). Considering sports activities most common among young children, it may be that these conditions are more likely to be met in the course of individual rather than team sports. That is, within the context of individual sports, young children may have less opportunity to 'switch off', may have a greater intra-personal orientation, and may receive more assistance from adults (e.g., parents, coaches, teachers) to help them direct and maintain their limited executive resources.

At the same time, the current results do not preclude the possibility that particular team sports may indeed provide self-regulatory benefits at this young age, which were mitigated by inclusion with team sports that are less beneficial for self-regulation. Further research that separates the type, frequency, and number of sports played is required to further investigate this possibility. Similarly, the current results do not preclude positive self-regulatory effects of team sports in later childhood, as an increasing shift to introduce more complex nuances of sport might tax and continue to challenge those cognitive components underlying successful self-regulation. That is, players must: hold in mind rules and strategies; inhibit the impulse to retain the ball without passing; adapt to ever-changing game demands; and, when plans fail, think flexibly to find a solution. As such, team sports in later childhood may introduce more of the challenge necessary to generate self-regulatory benefits.

Another possible explanation is that active children also tend to have supportive families (Kremarik, 2000) and thus it may not be sports per se, but high levels of parental engagement that increase both sports participation and self-regulation. Further, team sports participation at an early age is largely parent-driven (children may make the request, but participation will be largely parent-initiated or -influenced) (Howard \& Madrigal, 1990), as is a high-quality home 
learning environment that promotes self-regulatory development (Melhuish et al., 2015). Yet, the current data do not support this proposition as constituted. That is, self-regulatory benefits were not found amongst team sports participants who, one may presume, had similarly active and supportive families. As such, it is likely that the self-regulatory benefits of participation in individual sports, while limited in this study, are a function of particular characteristics of participation in those activities. As one example, an increased focus on turn-taking and intrapersonal control during individual sports, relative to team sports, may be beneficial for early development of self-regulation. Alternatively, it is also possible that families who enroll their child in individual sports might differ from those who enroll their child in team sports (e.g., recreational soccer vs. personal tennis lessons). As the current data are unable to evaluate this proposition, further research is required to evaluate this possibility.

Fewer studies have investigated the reverse directionality, or reciprocal nature, of the association between sports participation and self-regulation. What research exists has largely examined associations of EFs and 'elite-ness' in sport, usually among adults, indicating that those with better EFs are more likely to excel in sports relative to lower-EF participants (e.g., Vestberg et al., 2012; Voss et al., 2009). Yet, when reporting these results, the researchers noted their inability to determine whether high-EF individuals were more likely to become athletes and/or their EFs improved as a result of sports participation. Among slightly older children, there is evidence that teacher-rated self-regulation (i.e., attentional and emotional control) longitudinally predicts subsequent participation in sports (Piché et al., 2012). Our results extend this finding to young children, and comparison of team vs. individual sport, indicating an association of self-regulation with sports participation two years later. That is, children low in self-regulation tended to be less likely to engage in individual sports - and this finding was largely consistent for both boys and girls. Further, those high in early selfregulation were more likely to commence or maintain participation in team sports. Given the 
established health and development benefits of children's participation in youth sports (Eime et al., 2013; Fraser-Thomas et al., 2005), these findings suggest that targeted intervention approaches are needed to engage and support those with low self-regulation in high quality youth sports programs.

It is noted that this investigation was limited by available LSAC data. Specifically, child self-regulation was indexed by parent-, educator-, and observer-report rather than direct child assessment. However, this multi-source index has been successfully used as a reliable and robust predictor of a range of real-world outcomes in prior research, showing the ability of this early self-regulation factor to predict academic outcomes and unhealthy lifestyle choices in adolescence (Authors, 2017), as well as health, wealth, and criminality well into adulthood (Moffitt et al., 2011). While this conceptualization and operationalization of self-regulation is conceptually similar to some construals of temperament and social-behavioural development, recent theorizing positions self-regulation as contributing to (rather than synonymous with) these aspects of development (e.g., Rothbart, Ellis, \& Posner, 2004). Sport participation data was also limited to parent-report regarding participation in individual and team sports, but not the specific type or extent of participation. Further research is thus required to evaluate the impact of different sports on self-regulation, to identify characteristics that are essential for self-regulatory benefits. Research should also identify whether particular sports might have greater barriers to participation amongst those low in self-regulation, and how to address these barriers.

\section{Conclusion}

Our data on early childhood participation in individual and team sports, which is likely to capture the earliest point of participation, provides new insight into bidirectional associations between sports participation and self-regulation. Specifically, young children participating in individual sports showed slightly higher levels of self-regulation two years later, yet children 
with low self-regulation were less likely to participate in these sports. These results suggest that sports participation may both influence, and be influenced by, early self-regulation. The different findings for individual and team sports serve as a foundation and stimulus for new research to further clarify how early and later-life sports participation might influence selfregulatory development. Implications of these findings are significant given the health and developmental benefits of engaging in youth sport, and the established effects of early selfregulation on health, wealth, and pro-social outcomes well into adulthood. Targeted youth sports programs thus may be an engaging form of intervention for children who are low in self-regulation; however, such programs need to be made attractive and accessible to these (and all) children. 


\section{References}

ABS (Australian Bureau of Statistics). (2008). Information Paper: An Introduction to SocioEconomic Indexes for Areas (SEIFA) (cat. no. 2039.0). Retrieved August 162016 from http://www.abs.gov.au/ausstats/abs@.nsf/mf/2039.0

ABS (Australian Bureau of Statistics). (2012). Children's participation in cultural and leisure activities, Australia, Apr 2012 (cat. no. 4901.0). Retrieved May 262017 from http://www.abs.gov.au/ausstats/abs@.nsf/mf/4901.0

AHKA (Active Healthy Kids Australia). (2016). 2016 report card on physical activity for children and young people. Retrieved May 262017 from http://www.activehealthykidsaustralia.com.au/siteassets/documents/ahka-2016long_form-report-card.pdf

Authors. (2017). Early self-regulation, early self-regulatory change, and their longitudinal relations to adolescents' academic, health, and mental wellbeing outcomes. Manuscript submitted for publication in Journal of Pediatrics.

Baxter, J. A., \& Hand, K. (2013). Access to early childhood education in Australia (Research Report No. 24). Melbourne: Australian Institute of Family Studies.

Best, J. R. (2012). Exergaming immediately enhances children's executive function. Developmental Psychology, 48, 1501-1510. doi: 10.1037/a0026648

Carson, V., Hunter, S., Kuzik, N., Wiebe, S. A., Spence, J. C., ... Hinkley, T. (2015). Systematic review of physical activity and cognitive development in early childhood. Journal of Science and Medicine in Sport, 19, 573-578. doi: 10.1016/j.jsams.2015.07.011

Chang, Y. K., Tsai, Y. J., Chen, T. T., \& Hung, T. M. (2013). The impacts of coordinative exercise on executive function in kindergarten children: An ERP study. Experimental Brain Research, 225, 187-196. doi: 10.1007/s00221-012-3360-9 
Coe, D. P., Pivarnik, J. M., Womack, C. J., Reeves, M. J., \& Malina, R. M. (2006). Effects of physical education and activity levels on academic achievement in children. Medicine \& Science in Sports \& Exercise, 38(8), 1515-1519. doi:

10.1249/01.mss.0000227537.13175.1b

Cote, J., \& Hay, J. (2002). Children's involvement in sport: A developmental perspective. In J. M. Silva \& D. Stevens (eds.), Psychological Foundations of Sport (pp. 503-519). Boston, MA: Allyn \& Bacon.

Davis, C. L., Tomporowski, P. D., Boyle, C. A., Waller, J. L., Miller, P. H. ... Gregoski, M. (2007). Effects of aerobic exercise on overweight children's cognitive functioning. Research Quarterly for Exercise and Sport, 78(5), 510-519. doi: $10.1080 / 02701367.2007 .10599450$

Di Russo, F., Bultrini, A., Brunelli, S., Delussu, A. S., Polidori, L., ... Spinelli, D. (2010). Benefits of sports participation for executive function disabled atheletes. Journal of Neurotrauma, 27, 2309-2319. doi: 10.1089/neu.2010.1501

Diamond, A. (2016). Why assessing and improving executive functions early in life is critical. In J. A. Griffin, P. McCardle, \& L. S. Freund (eds.), Executive Function in Preschool-Age Children: Integrating Measurement, Neurodevelopment, and Translational Research (pp. 11-43). Washington, DC: American Psychological Association. doi: 10.1037/14797-002

Diamond, A., \& Lee, K. (2011). Interventions shown to aid executive function development in children 4-12 years old. Science, 333, 959-964. doi: 10.1126/science.1204529

Diamond, A., \& Ling, D. S. (2016). Conclusions about interventions, programs, and approaches for improving executive functions that appear justified and those that, despite much hype, do not. Developmental Cognitive Neuroscience, 18, 34-48. doi: 10.1016/j.den.2015.11.005 
Dwyer, T., Sallis, J. F., Blizzard, L., Lazarus, R., \& Dean, K. (2001). Relation of academic performance ot physical activity and fitness in children. Pediatric Exercise Science, 13(3), 225-237. doi: 10.1123/pes.13.3.225

Eccles, J. S., \& Barber, B. L. (1999). Student council, volunteering, basketball, or marching band: What kind of extracurricular involvement matters? Journal of Adolescent Research, 14(1), 10-43. doi: 10.1177/0743558499141003

Eime, R. M., Young, J. A., Harvey, J. T., Charity, M. J., \& Payne, W. R. (2013). A systematic review of the psychological and social benefits of participation in sport for children and adolescents: Informing development of a conceptual model of health through sport. International Journal of Behavioral Nutrition and Physical Activity, 10, 121. doi: $10.1186 / 1479-5868-10-98$

Fraser-Thomas, J. L., Cote, J., \& Deakin, J. (2005). Youth sport programs: An avenue to foster positive youth development. Physical Education and Sport Pedagogy, 10, 19-40. doi: $10.1080 / 1740898042000334890$

Hansen, D., Larson, R., \& Dworkin, J. (2003). What adolescents learn in organized youth activities. Journal of Research on Adolescence, 13, 25-55. doi: 10.1111/15327795.1301006

Harrison, L., Ungerer, J., Smith, G., Zubrick, S., \& Wise, S., ... LSAC Research Consortium. (2009). Child care and early education in Australia: The Longitudinal Study of Australian Children (Social Policy Research Paper No. 40). Canberra: Department of Families, Housing, Community Services and Indigenous Affairs. Retrieved May 262017 from http://www.fahcsia.gov.au/sites/default/files/documents/05_2012/sprp_40.pdf

Heckman, J. (2006). Skill formation and the economics of investing in disadvantaged children. Science, 312, 1900-1902. doi: 10.1126/science.1128898 
Hofmann, W., Schmeichel, B. J., \& Baddeley, A. D. (2014). Executive functions and selfregulation. Trends in Cognitive Sciences, 16, 174-180. doi: 10.1016/j.tics.2012.01.006

Holbrook, M. B., Chestnut, R. W., Oliva, T. A., \& Greenleaf, E. A. (1984). Play as a consumption experience: The roles of emotions, performance, and personality in the enjoyment of games. Journal of Consumer Research, 11(2), 728-739. doi: $10.1086 / 209009$

Holt, N. L., \& Nelly, K. C. (2011). Positive youth development through sport: A review. La Revista Iberoamericana de Psicología del Ejercicio y el Deporte, 6, 299-316.

Howard, D. R., \& Madrigal, R. (1990). Who makes the decision: The parent or the child? The perceived influence of parents and children on the purchase of recreation services. Journal of Leisure Research, 22, 244-258.

Jacobsen, J., \& Matthaeus, L. (2014). Athletics and executive functioning: How athletic participation and sport type correlate with cognitive performance. Psychology of Sport and Exercise, 15, 521-527. doi: 10.1016/j.psychsport.2014.05.005

Kremarik, F. (2000). A family affair: Children's participation in sports. Canadian Social Trends, 58, 20-24.

Lakes, K. D., \& Hoyt, W. T. (2004). Promoting self-regulation through school-based martial arts training. Journal of Applied Developmental Psychology, 25, 283-302. doi: 10.1016/j.appdev.2004.04.002

Long, B. C. (1985). Stress-management interventions: A 15-month follow-up of aerobic conditioning and stress inoculation training. Cognitive Therapy and Research, 9, 471478. doi: 10.1007/BF01173094

Magee, C. A., Caputi, P., \& Iverson, D. C. (2012). Are parents' working patterns associated with their child's sleep? An analysis of dual-parent families in Australia. Sleep and Biological Rhythms, 10, 101-108. doi: 10.1111/j.1479-8425.2011.00530.x 
Melhuish, E., Ereky-Stevens, K., Petrogiannis, K., Ariescu, A., Penderi, E., ... Leseman, P. (2015). A review of research on the effects of Early Childhood Education and Care (ECEC) upon child development. Retrieved August 162016 from: http://ececcare.org/resources/publications.

Moffitt, T., Arsenault, L., Belsky, D., Dickson, N., Hancox, R. J., ... Caspi, A. (2011). A gradient of childhood self-control predicts health, wealth, and public safety. Proceedings of the National Academy of Sciences, 108, 2693-2698. doi: 10.1073/pnas.1010076108

Montroy, J. L., Bowles, R. P., Skibbe, L. E., McClelland, M. M., \& Morrison, F. J. (2106). The development of self-regulation across early childhood. Developmental Psychology, 52(11), 1744-1762. doi: 10.1037/dev0000159

Piché, G., Fitzpatrick, C., \& Pagani, L. S. (2012). Kindergarten self-regulation as a predictor of body mass index and sports participation in fourth grade students. Mind, Brain, and Education, 6(1), 19-26. doi: 10.1111/j.1751-228X.2011.01132.x

Rothbart, M. K., Ellis, L. K., \& Posner, M. I. (2004). Temperament and self-regulation. In Handbook of self-regulation: Research, theory, and applications (pp. 441-460). New York: Guilford Press.

Sanson, A., Nicholson, J., Ungerer, J., Zubrick, S., \& Wilson, K. (2002). Introducing the Longitudinal Study of Australian Children - Discussion paper no. 1. Australian Institute of Family Studies. doi: hdl.handle.net/10620/3174

Schnohr, P., Kristensen, T. S., Prescott, E., \& Scharling, H. (2005). Stress and life dissatisfaction are inversely associated with jogging and other types of physical activity in leisure time - The Copenhagen City Heart Study. Scandinavian Journal of Medicine \& Science in Sports, 15, 107-112. doi: 10.1111/j.1600-0838.2004.00394.x

Shephard, R. J. (1997). Curricular physical activity and academic performance. Pediatric Exercise Science, 9(2), 113-126. doi: 10.1123/pes.9.2.113 
Vella, S. A., Magee, C. A., \& Cliff, D. P. (2015). Trajectories and predictors of health-related quality of life during childhood. Journal of Pediatrics, 167, 422-427. doi: 10.1016/j.jpeds.2015.04.079

Vestberg, T., Gustafson, R., Maurex, L., Ingvar, M., \& Petrovic, P. Executive functions predict the success of top-soccer players. PLoS one, 7, e34731. doi: 10.1371/journal.pone.0034731

Voss, M. W., Kramer, A. F., Basak, C., Prakash, R. S., \& Roberts, B. (2009) Are expert athletes 'expert' in the cognitive laboratory? A meta-analystic review of cognition and sport exercise. Applied Cognitive Psychology, 24, 812-826. doi: 10.1002/acp.1588

Wankel, L. M., \& Berger, B. G. (1990). The psychological and social benefits of sport and physical activity. Journal of Leisure Research, 22, 167-182.

Wass, S. V., Scerif, G., \& Johnson, M. H. (2012). Training attentional control and working memory - is younger better? Developmental Review, 32(4), 360-387. doi: 10.1016/j.dr.2012.07.001

Whitley, R. L. (1999). Those 'Dumb Jocks' Are at It Again: A Comparison of the Educational Performances of Athletes and Nonathletes in North Carolina High Schools from 1993 through 1996. The High School Journal, 82(4), 223-233.

Wiersma, L., \& Fifer, A. "The schedule has been tough but we think it's worth it": The joys challenges, and recommendations of youth sport parents. Journal of Leisure Research, $40,505-530$.

Youngstedt, S. D. (2005). Effects of exercise on sleep. Clinics in Sports Medicine, 24, 355365. doi: 10.1016/j.csm.2004.12.003 
Table 1

Self-Regulation Item Correspondences between Moffitt et al. (2011) and Current Study

\begin{tabular}{|c|c|c|}
\hline Factor & Moffitt et al. (2011) items & Corresponding LSAC items \\
\hline Impulsive & Flies off handle ${ }^{P, T}$ & Often has temper tantrums/hot tempers ${ }^{\mathrm{P}, \mathrm{T}}$ \\
\hline \multirow[t]{3}{*}{ Aggression } & Fights $P, T$ & Often fights with other children or bullies \\
\hline & Requires attention ${ }^{\mathrm{O}}$ & them $\mathrm{P}, \mathrm{T}$ \\
\hline & & Often argumentative with adults $\mathrm{P}, \mathrm{T}$ \\
\hline \multirow[t]{5}{*}{ Hyperactivity } & Runs and jumps about ${ }^{\mathrm{P}, \mathrm{T}}$ & Restless, overactive, cannot stay still for \\
\hline & Cannot settle ${ }^{\mathrm{P}, \mathrm{T}}$, restless ${ }^{\mathrm{O}}$ & long $\mathrm{P}, \mathrm{T}$ \\
\hline & "On the go", "driven by a motor" $\mathrm{P}, \mathrm{T}$ & Constantly fidgeting or squirming ${ }^{\mathrm{P}, \mathrm{T}}$ \\
\hline & Difficulty sitting still ${ }^{\mathrm{P}, \mathrm{T}}$ & If this child is upset, it is hard to comfort \\
\hline & Has short attention span ${ }^{\mathrm{P}, \mathrm{T}}$ & him/her ${ }^{\mathrm{P}, \mathrm{T}}$ \\
\hline
\end{tabular}

Lack of

Persistence

\& Inattention
Fails to finish tasks ${ }^{\mathrm{P}, \mathrm{T}}$, trouble sticking to a task $\mathrm{s}$

Difficulty sticking to activity ${ }^{\mathrm{P}, \mathrm{T}}$, brief attention to task ${ }^{\mathrm{O}}$

Lacks persistence in reaching goals ${ }^{\mathrm{O}}$

Easily distracted ${ }^{\mathrm{P}, \mathrm{T}}$, difficulty paying attention $^{\mathrm{s}}$
The child likes to complete one task or activity before going on to the next (reversed) ${ }^{\mathrm{P}, \mathrm{T}}$

Sees takes through to the end, good attention span (reversed) ${ }^{\mathrm{P}, \mathrm{T}}$

The child stays with an activity (e.g., puzzle, construction, kit, reading) for a long time (reversed) ${ }^{\mathrm{P}, \mathrm{T}}$

Easily distracted, concentration wanders $\mathrm{P}, \mathrm{T}, \mathrm{O}$

\begin{tabular}{|c|c|c|}
\hline Impulsivity & $\begin{array}{l}\text { Acts before thinking }{ }^{\mathrm{P}, \mathrm{T}} \text {, impulsive }{ }^{\mathrm{O}} \\
\text { Has difficulty awaiting turn }{ }^{\mathrm{P}, \mathrm{T}} \\
\text { Sits excessively between activities }{ }^{\mathrm{P}, \mathrm{T}} \\
\text { Difficulty waiting turn }{ }^{\mathrm{S}} \\
\text { Talking while others are still talking }{ }^{\mathrm{S}} \\
\text { Low frustration tolerance }^{\mathrm{O}}\end{array}$ & $\begin{array}{l}\text { Can stop and think things out before } \\
\text { acting (reversed) }{ }^{\mathrm{P}, \mathrm{T}} \\
\text { Shares readily with other children } \\
\quad \text { (reversed) }{ }^{\mathrm{P}, \mathrm{T}} \\
\text { Degree of negative mood (withdrawn, } \\
\text { uncooperative, sulky, seeming upset, } \\
\text { angry) to interview } \mathrm{O}\end{array}$ \\
\hline
\end{tabular}

Note. Factor names parallel those adopted by Moffitt et al. (2011). Notation following items indicates the source of the data. ${ }^{\mathrm{P}}$ parent rating. ${ }^{\mathrm{T}}$ teacher rating. ${ }^{\mathrm{O}}$ observer rating. ${ }^{\mathrm{S}}$ self-rating. 
Table 2

Adjusted mean self-regulation scores stratified by demographic variables and sports participation.

\begin{tabular}{|c|c|c|c|}
\hline \multirow[t]{2}{*}{ 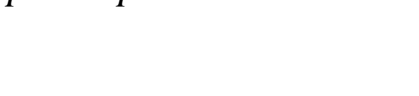 } & \multirow[b]{2}{*}{$\mathbf{N}$} & \multicolumn{2}{|c|}{ Mean Self-Regulation Score (95\% CI) } \\
\hline & & Age 4 & Age 6 \\
\hline Total Sample & 4385 & $0.006(-0.002,0.13)$ & $0.010(0.002,0.019)$ \\
\hline \multicolumn{4}{|l|}{ Sex } \\
\hline Male & 2178 & $-0.100(-0.111,-0.090)$ & $-0.120(-0.132,-0.108)$ \\
\hline Female & 2055 & $0.120(0.110,0.129)$ & $0.149(0.140,0.160)$ \\
\hline \multicolumn{4}{|l|}{ Primary parent education } \\
\hline Less than High School & 450 & $-0.094(-0.114,-0.075)$ & $-0.110(-0.130,-0.090)$ \\
\hline High School & 1301 & $-0.058(-0.071,-0.045)$ & $-0.047(-0.061,-0.032)$ \\
\hline Tertiary & 2481 & $0.056(0.046,0.066)$ & $0.059(0.048,0.071)$ \\
\hline \multicolumn{4}{|l|}{ Time 1 sport participation } \\
\hline No & 1635 & $-0.087(-0.218,0.044)$ & $0.041(-0.071,0.152)$ \\
\hline Yes & 2750 & $0.034(-0.097,0.166)$ & $0.060(-0.052,0.172)$ \\
\hline \multicolumn{4}{|c|}{ Time 1 team sport participation } \\
\hline No & 3798 & $-0.038(-0.169,0.094)$ & $0.053(-0.058,0.164)$ \\
\hline Yes & 587 & $0.008(-0.130,0.145)$ & $0.031(-0.85,0.148)$ \\
\hline \multicolumn{4}{|c|}{ Time 1 individual sport participation } \\
\hline No & 1837 & $-0.072(-0.203,0.060)$ & $0.034(-0.077,0.146)$ \\
\hline Yes & 2548 & $0.040(-0.092,0.172)$ & $0.075(-0.037,0.188)$ \\
\hline \multicolumn{4}{|l|}{ Sport status time 1 to time 2} \\
\hline Nonparticipant & 629 & $-0.153(-0.161,-0.145)$ & $-0.144(-0.149,-0.138)$ \\
\hline Dropout & 426 & $0.040(0.036,0.045)$ & $0.002(-0.004,0.008)$ \\
\hline Commencer & 854 & $-0.067(-0.076,-0.059)$ & $-0.049(-0.056,-0.042)$ \\
\hline Participant & 2194 & $0.067(0.060,0.074)$ & $0.073(0.065,0.081)$ \\
\hline \multicolumn{4}{|c|}{ Team sport status time 1 to time 2} \\
\hline Nonparticipant & 2170 & $0.002(-0.005,0.009)$ & $0.010(0.003,0.174)$ \\
\hline Dropout & 152 & $-0.010(-0.010,-0.010)$ & $-0.064(-0.064,-0.064)$ \\
\hline Commencer & 1378 & $0.016(0.010,0.023)$ & $0.030(0.022,0.037)$ \\
\hline Participant & 403 & $-0.002(-0.011,0.007)$ & $-0.035(-0.046,-0.025)$ \\
\hline \multicolumn{4}{|c|}{ Individual sport status time 1 to time 2} \\
\hline Nonparticipant & 1048 & $-0.122(-0.130,-0.113)$ & $-0.137,(-0.143,-0.130)$ \\
\hline Dropout & 750 & $0.048(0.041,0.054)$ & $0.037(0.030,0.043)$ \\
\hline Commencer & 625 & $-0.053(-0.962,-0.044)$ & $-0.034(-0.043,-0.027)$ \\
\hline Participant & 1680 & $0.082(0.074,0.090)$ & $0.098(0.089,0.107)$ \\
\hline
\end{tabular}

Note. Not all children in each category have self-regulation data at both time points. Total sample sizes are reported. 